\title{
SUPRA AND INTRACONDYLAR OPEN FRACTURE OF THE FEMUR IN A MOTOCROSS ATHLETE: CASE REPORT
}

Jorge Sayum Filho', Jorge Sayum², Rogério Teixeira de Carvalho' ${ }^{1}$, Alexandre Nicolini' ${ }^{1}$, Marcelo Mitsuro Matsuda', Wu Tu Cheng ${ }^{3}$, Moisés Cohen ${ }^{4}$

\section{ABSTRACT}

The authors report the case of a patient (amateur motocross competitor) who suffered a fall during a motocross competition resulting in a supra and intracondylar open fracture in the right femur.

Keywords - Femoral Fractures; Fractures, Open; Athletes

\section{INTRODUCTION}

The distal femur comprises the region of the distal third of this bone. It starts where the femoral canal widens and the cortical bone becomes thin, and extends down to the joint.

Fractures of the distal femur have bimodal incidence, such that they are high-energy events among young male adults and low-energy events among elderly women. They account for $6 \%$ of femoral fractures; $20 \%$ of the cases are single lesions and almost $50 \%$ of the joint fractures are exposed.

\section{CASE REPORT}

The patient was a 30-year-old white man who was an amateur motocross competitor who was born and was living in São Paulo. He sought the services of the Sports Traumatology Center (CETE) of the Department of Orthopedics and Traumatology (DOT), Federal University of São Paulo (UNIFESP) with a complaint of pain in his right knee and thigh that started around one hour earlier, after having suffered a fall from the motorbike during a competition.

The patient reported that his right knee and thigh started to hurt one hour earlier, when he fell from his motorbike after jumping over an obstacle. Because of his intense pain and inability to get up, he was removed from the motocross trail by the rescue service.

On physical orthopedic examination, the patient presented a cutting and bruising injury of $4 \mathrm{~cm}$ in length on the anterior region of the right knee and thigh; deformity of the thigh and severe bleeding; functional incapacity because of the pain; presence of a fixed splint; good distal perfusion; palpable peripheral pulse $(4+/ 4+)$ and sensitivity that was difficult to assess because of the pain.

The clinical and surgical teams evaluated the patient in accordance with the principles of Advanced Trauma Life Support (ATLS) and released the patient. The vascular team evaluated the case and, after performing a Doppler ultrasound examination, also released the patient. The orthopedics team requested radiographs of

1 - Attending Physician at the Sports Traumatology Center (CETE), Department of Orthopedics and Traumatology, Federal University of São Paulo (Unifesp), São Paulo, SP, Brazil.

2 - Head Physician of the Department of Orthopedics and Traumatology, Assunção Hospital and Maternity Hospital (HMA), São Bernardo do Campo, SP, Brazil.

3 - Attending Physician in the Department of Orthopedics and Traumatology, Assunção Hospital and Maternity Hospital (HMA), São Bernardo do Campo, SP, Brazil.

4 - Full Professor in the Department of Orthopedics and Traumatology, Unifesp; Head of the Sports Traumatology Center (CETE), São Paulo, SP, Brazil.

Work performed at the Sports Traumatology Center (CETE), Department of Orthopedics and Traumatology (DOT), Federal University of São Paulo (Unifesp).

Correspondence: Rua França Pinto 186, apto. 61, Vila Mariana, 04016-001 São Paulo, SP. E-mail: jorgesayumfilho@hotmail.com

Work received for publication: July 25, 2010; accepted for publication: November 3, 2010

The authors declare that there was no conflict of interest in conducting this work 
the right knee and thigh, which showed a fracture in the femur. For a better assessment of the fracture, computed tomography was also performed. In this manner, a diagnosis of exposed intracondylar fracture of the right femur was made. Using the AO classification system, the fracture was classified as Gustillo 2.33C-3.

It was decided to perform emergency surgical treatment. The patient was administered spinal anesthesia and was placed in horizontal dorsal decubitus. An anterior approach was chosen because the exposed wound was above this. With the aid of the video device, and after exhaustive surgical cleaning, the joint fracture was reduced. Following this, osteosynthesis of the joint fractures and then those of the metaphysis and diaphysis was performed with the aid of a femoral posterior cruciate ligament plate.

The patient remained in hospital for five days for intravenous antibiotic therapy (ciprofloxacin), without immobilization. The stitches were removed after 14 days, and partial progressive load-bearing was allowed from this time onwards. Physiotherapy, which had started on the second day after the operation, continued for eight months. At this point, the patient was discharged and returned to his sport.

\section{DISCUSSION}

According to the literature, fractures of the distal femur have bimodal incidence, such that they are highenergy events among young male adults and low-energy events among elderly females. They account for $6 \%$ of femoral fractures; $20 \%$ of the cases are single lesions and almost $50 \%$ of the joint fractures are exposed. The associated lesions that have been reported include vascular lesions in 3\%, nerve lesions in $1 \%$, lesions relating to the patella in $15 \%$ and ligament lesions and pathological conditions relating to the joint in 20 to $70 \%{ }^{(1-4)}$.

The diagnostic suspicion comes from clinical examination, and meticulous neurovascular examination is essential. Doppler ultrasound and angiography may be necessary. Magnetic resonance imaging and computed tomography are not essential, but may be necessary for better assessment of the fracture ${ }^{(2,4-6)}$.

The classifications most used are Gustillo for exposed fractures and $\mathrm{AO}$ for femoral fractures.

Conservative treatment is only justified for patients who are not in a condition to undergo surgery, debilitated patients and cases of incomplete fractures without deviation. The treatment of choice is surgical, and this has the aims of achieving anatomical reconstruction of the joint surfaces, restoration of the axial and rotational alignment, stable fixation of the condyles to the diaphysis and immediate functional care. Anatomical joint reduction should be performed before osteosynthesis of the diaphyseal metaphysis. According to AO, a lateral approach is most recommended, but a medial anterior approach may also be used. A variety of osteosynthesis materials can be used, including: posterior cruciate ligament plates, laminas, DCS, LISS, external fixators and cannulated screws, among others ${ }^{(5-7)}$.

The classifications that exist include: axial and rotational misalignment, genu recurvatum, varus slide, dehiscence of the operative wound, stiffness, loss of range of motion, infection, pseudarthrosis, thrombosis and compartment syndrome, among others ${ }^{(7)}$.

For all these reasons, this case of an exposed supra-intracondylar fracture of the femur in a motocross competitor was reported. The case was diagnosed and treated in accordance with the literature (Figures 1,2 and 3).

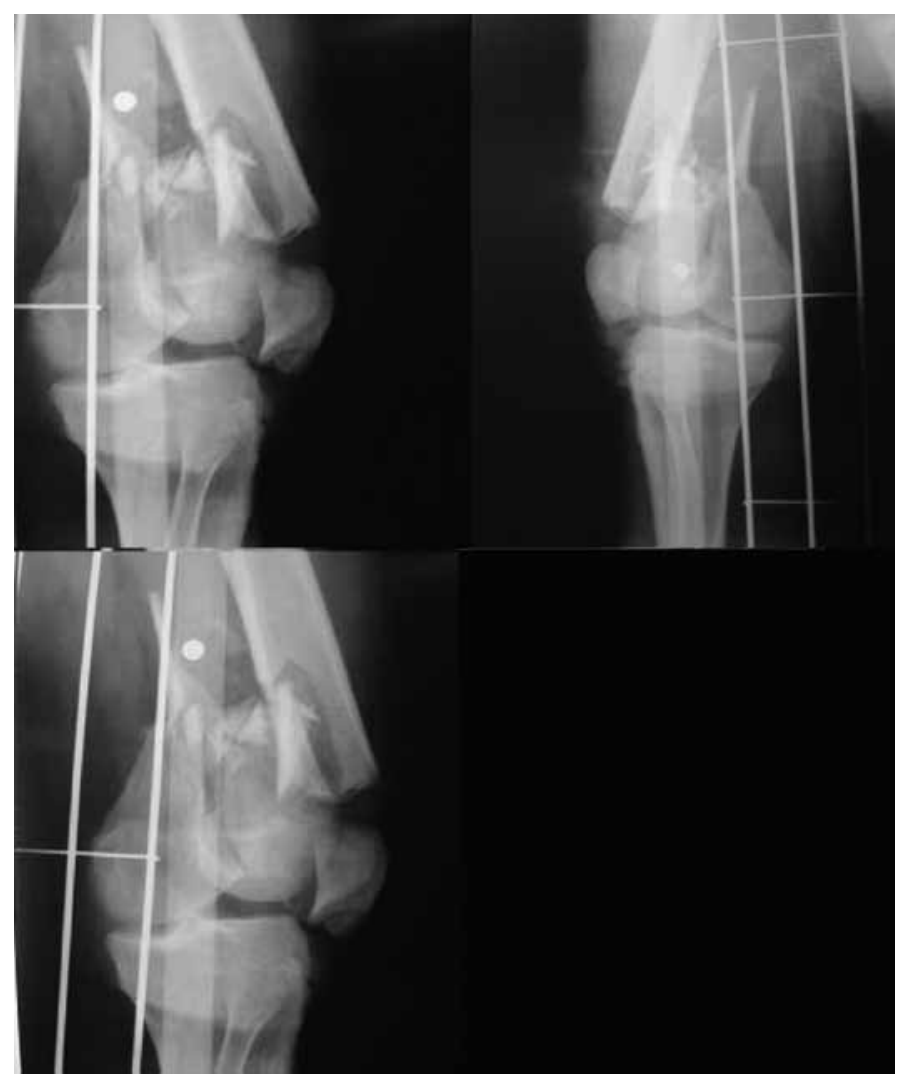

Figure 1 - Preoperative radiographs. 


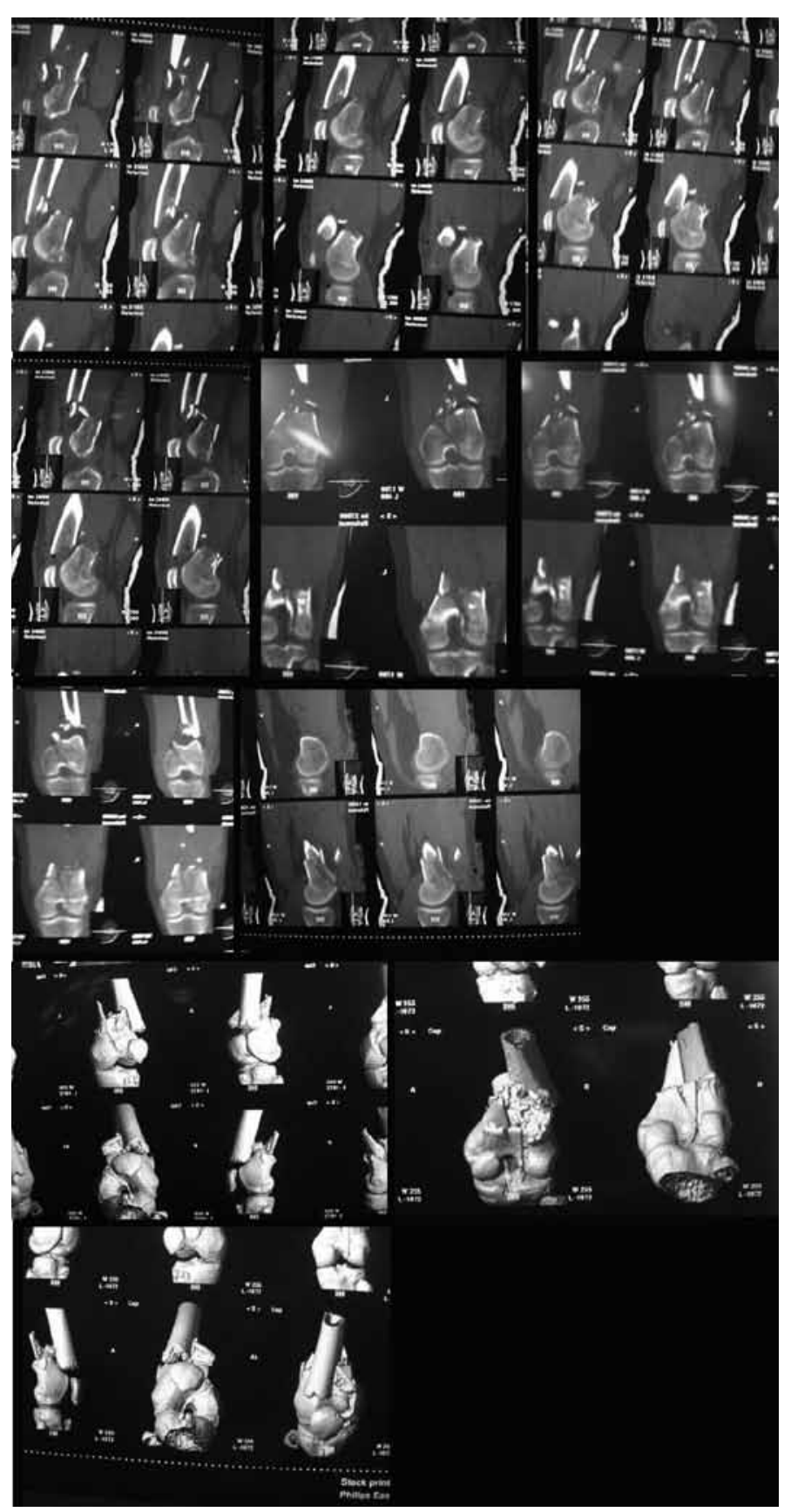

Figure 2 - Preoperative tomography.

\section{REFERENCES}

1. Lindvall EM. Distal Femur Fractures. In: Scott WN. Surgery Of The Knee. Philadelphia, United States of America: Churchill Livingstone; 2006. p. 1119-32.

2. Lidge RT, Problems and complications in arthroscopy. In: Casscells SW. Arthroscopy:diagnostic and surgical practice. Philadelphia: Lea \& Febiger; 1984. p.102-9.

3. Sprague NF.Complications in arthroscopy. New York: Raven Press; 1989.

4. Tovey C, Wyatt S. Diagnosis, investigation, and management of deep vein

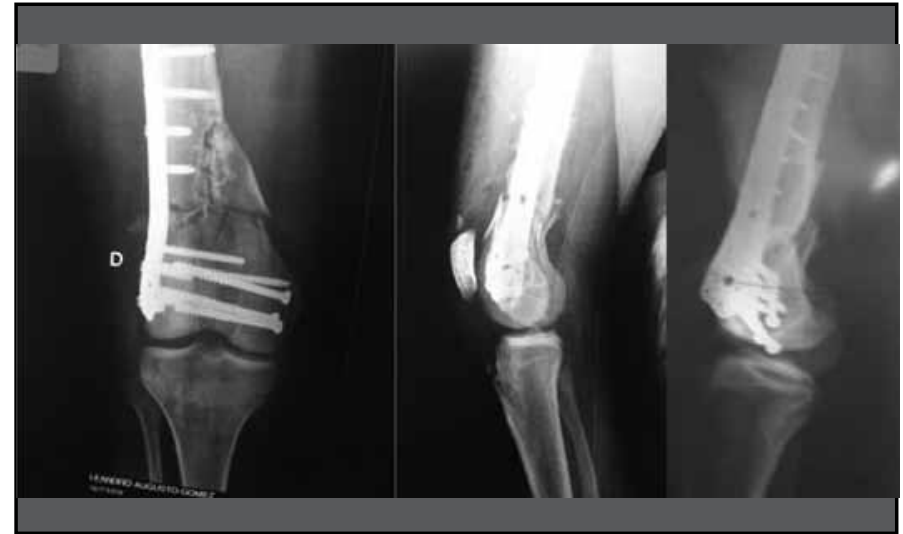

Figure 3 - Postoperative radiographs. 